\title{
Manutenção da diversidade agrícola em assentamentos rurais: um estudo de caso em Moji-Mirim - SP, Brasil
}

\author{
Carolina Ribeiro Araújo * \\ Maria Christina de Mello Amorozo \\ Instituto de Biociências, Universidade Estadual Paulista "Julio de Mesquita Filho" \\ Campus Rio Claro, Rio Claro - SP, Brasil \\ * Autor para correspondência \\ Rua Iperoig, 374, apto E, CEP 05016-000, São Paulo - SP, Brasil \\ cranet2003@yahoo.com.br
}

Submetido em 10/04/2011

Aceito para publicação em 17/04/2012

\section{Resumo}

Este estudo investigou se os agricultores, quando estabelecidos em assentamentos rurais, mantêm algumas características tradicionais em relação à diversidade de cultivos e circulação de material de plantio. Seus objetivos foram realizar um levantamento etnobotânico das espécies e variedades e analisar a dinâmica de circulação de sementes e propágulos. Foram levantadas no total 139 variedades de cultivos alimentares (55 espécies/28 famílias), sendo $87 \%$ delas destinadas ao autoconsumo; $54 \%$ das variedades são oriundas de Minas Gerais, estado natal da maioria dos entrevistados. O número de variedades cultivadas por unidade doméstica variou de 17 a 54. A circulação informal e livre de material de plantio é a forma mais importante de aquisição. A rede de circulação é bastante ativa, evidenciando um potencial para o manejo da diversidade dos cultivos, com destaque para a contribuição dos assentados para conservação e valorização das variedades tradicionais.

Palavras-chave: Agrobiodiversidade; Agricultura de subsistência; Assentamento rural; Circulação de sementes e propágulos

\section{Abstract}

Maintenance of agricultural diversity in rural settlements - a case study in Moji-Mirim, São Paulo, Brazil. This paper investigated whether farmers, when established in rural settlements, keep some traditional features with regard to crops diversity and circulation of planting material. Its aims were to make an ethnobotanical survey of species and varieties and analyze the dinamics of seeds and propagules circulation. A total of 139 varieties of food crops ( 55 species/28 families) were found, being $87 \%$ of them intended for self-consumption; $54 \%$ of varieties come from Minas Gerais, home state of most respondents. The number of varieties grown per household ranged from 17 to 54 . The informal and free circulation of planting material is the most important way of acquisition. The circulation network is very active, showing a potential for the management of crops diversity, with emphasis on the contribution of settlers to the maintenance and valorization of traditional varieties.

Key words: Agro-biodiversity; Circulation of seeds and propagules; Rural settlement; Subsistence agriculture 


\section{Introdução}

Ao longo de milhares de anos de prática da agricultura, grupos de cultivadores domesticaram diversas espécies e desenvolveram inúmeras variedades para várias finalidades, mas especialmente alimentares (AMOROZO, 1996); uma parte desta diversidade ainda é mantida em agroecossistemas tradicionais ${ }^{1}$, por comunidades autóctones, indígenas e não indígenas (BRUSH, 2000; MAXTED et al., 2002).

Em comunidades tradicionais, que praticam agricultura de subsistência, a existência dos recursos domesticados resulta de um processo cumulativo de manutenção, aquisição, amplificação da diversidade (EMPERAIRE; PERONI, 2007; PERONI et al., 2007; MARTINS; OLIVEIRA, 2009) e também perda, tanto de conhecimento como de material fitogenético ao longo das gerações, com a circulação deste material praticada em um determinado espaço geográfico (EMPERAIRE, 2006). A manutenção do conjunto de variedades e o mecanismo de intercâmbio entre os agricultores são importantes para minimização de riscos e garantir o suprimento de sementes (AMOROZO, 1996).

O processo de modernização agrícola afetou grande parte do espaço agrícola brasileiro, provocando o abandono de formas tradicionais de produção, causando impactos em relação à diversidade genética. Por isso, para se prevenir o processo de erosão genética, tem sido proposta a conservação de recursos fitogenéticos na própria situação onde eles se desenvolveram (in situ e on farm $)^{2}$.

\footnotetext{
"Sistemas agrícolas tradicionais" normalmente se referem ao sistema de produção voltado principalmente para a subsistência do grupo de produtores, com a utilização de insumos locais e tecnologia característica. Estes grupos de pessoas geralmente têm relações de parentescos e cooperação, e possuem grande conhecimento do ambiente onde vivem. As plantas cultivadas por comunidades deste gênero são essenciais para o fornecimento da base alimentar do grupo, e, portanto, para sua continuidade (AMOROZO, 2002).

2 De acordo com Brown et al. (2000), "a conservação in situ da biodiversidade agrícola é a manutenção da diversidade presente nas e entre populações das muitas espécies usadas diretamente na agricultura ou usadas como fontes de genes nos habitats onde tal diversidade se originou e continua a crescer". A conservação on farm é um termo aplicado à conservação, nos sistemas agrícolas, das espécies cultivadas, enquanto a conservação ex situ é a que é feita fora dos habitats naturais ou dos sistemas produtivos.
}

Muitos cientistas e organizações reconhecem que os agroecossistemas tradicionais são adequados para a conservação on farm da biodiversidade agrícola. (BELLON, 2001; SUBEDI et al., 2003; AMOROZO, 2008), enquanto outros são céticos sobre a consecução deste objetivo, devido ao rápido avanço tecnológico e econômico atual, que altera estes sistemas (JANA, 1999). Porém, pouca pesquisa foi realizada até o momento para avaliar se agricultores tradicionais que saem de seus locais de origem podem também, e até que ponto, manter diversidade de cultivos em outros espaços, por exemplo, quintais em áreas periurbanas (BROOKFIELD, 2001; BIROL, 2006; EMPERAIRE; ELOY, 2008) e assentamentos rurais (GAVIOLI, 2009).

A modernização da agricultura no Brasil contribuiu para a exclusão dos pequenos agricultores familiares e de sociedades tradicionais; por isso, uma parcela expressiva da população rural deixou o campo, em direção a áreas de maior dinamismo enconômico e portanto maior oferta de empregos (MARTINE; GARCIA, 1987), entre elas o interior do estado de São Paulo. Muitas dessas pessoas juntam-se a movimentos sociais a favor da reforma agrária e vão se estabelecer em assentamentos rurais (BERGAMASCO; NORDER, 2003).

Atualmente, existem, no Brasil, mais de 900.000 famílias assentadas, distribuídas em mais de 7.600 assentamentos rurais, ocupando uma área de quase 65 milhões de hectares (GIRARDI; FERNANDES, 2008). O estado de São Paulo contabiliza cerca de 210 assentamentos, com mais de 12.500 famílias assentadas e uma área total de cerca de 275.000 ha (INCRA, 2008a; 2008b). Tais assentamentos rurais, atualmente, constituem um grande desafio para o estabelecimento de sistemas agrícolas sustentáveis, do ponto de vista socioeconômico e ambiental, como os de orientação agroecológica. Um dos pontos centrais para a sustentabilidade é a autonomia dos agricultores. A agrobiodiversidade, mantida localmente, é de grande interesse neste sentido, porém trabalhos que avaliem agrobiodiveridade em assentamentos rurais são praticamente inexistentes. A proposta deste estudo é investigar esta questão a partir de uma perspectiva etnobotânica, abordando agricultores assentados oriundos de áreas de agricultura tradicional de subsistência. A Etnobotânica, por articular aspectos 
socioculturais e agroecológicos, é especialmente útil em estudos deste tipo, uma vez que a dinâmica e manutenção do acervo de variedades cultivadas é indissociável do conhecimento local sobre elas e das interações sociais que moldam e mantêm este acervo (EMPERAIRE, 2006; EMPERAIRE; PERONI, 2007; AMOROZO, 2000, entre outros).

Desta forma, este estudo teve como objetivo verificar se agricultores que antes praticavam agricultura de subsistência, ou que vieram de áreas de agricultura de subsistência, quando estabelecidos em um assentamento rural, mantêm algumas das características tradicionais com relação à diversidade de cultivos e à circulação de material de plantio. Com esta finalidade, foi realizado: 1) levantamento etnobotânico das espécies e variedades de plantas alimentícias; 2) registro e análise da dinâmica de circulação de sementes e propágulos destas plantas.

\section{Material e Métodos}

\section{Área de estudo}

Este estudo foi realizado no assentamento rural XII de Outubro - Horto Vergel - localizado em Moji-Mirim no estado de São Paulo (22²5'55'S e 46 57'28”W). O município tem $499,12 \mathrm{~km}^{2}$ de área e 81.467 habitantes, sendo 73.099 residentes na área urbana e 8.368 na área rural (IBGE, 2000). Segundo a classificação Köeppen, o clima da região é do tipo Cwa (verões chuvosos e quentes, inverno frio e seco); o relevo, suave ondulado, é propício para a agricultura (CEPAGRI, 2011).

O assentamento foi formado a partir de um movimento social de luta pela terra, contando com o suporte logístico e orientação sindical da CUTCONTAG.. Foi regularizado em 1998, em área do Horto Florestal Vergel, pertencente às Ferrovias Paulistas SA (FEPASA). Está dividido em 90 lotes familiares, que têm área de 8,7ha; as áreas úteis, onde já ocorreu o corte do eucalipto, variam bastante (ITSP, 2006).

Segundo dados coletados no campo, o assentamento tem 145 famílias (1,6 por lote, em média). Estas famílias são originárias de diversos municípios paulistas, como: Moji Mirim, Moji Guaçu, Conchal, Estiva Gerbi,
Campinas entre outros (SOARES, 2005), bem como dos estados de Minas Gerais, Paraná, Mato Grosso, Piauí. Dentre estes agricultores, alguns praticam agricultura de subsistência, outros plantam para vender no comércio local ou para o CEASA (Centrais de Abastecimentos de Campinas SA). As principais espécies cultivadas são a mandioca (de mesa e para indústria), milho, arroz, feijão, amendoim, as hortaliças, a banana, outras frutíferas (como acerola, laranja, limão, mamão formosa, manga e maracujá azedo) (ITESP, 2006).

\section{Coleta de dados}

Foi utilizado o método de estudo de caso, abordagem que permite analisar detalhadamente uma situação particular (GODOY, 1995; GIL, 1999), enfocando uma parcela dos agricultores estabelecidos no assentamento, que eram originários de áreas de agricultura de subsistência. A seleção de agricultores foi feita a partir do estudo de Cultrera et al. (2006), que identificaram os lotes em que os assentados eram oriundos de áreas de agricultura tradicional (30). Destes, foram selecionados para o presente estudo, por amostragem por julgamento (BERNARD, 1998), dez lotes onde os agricultores ainda praticavam agricultura de subsistência e os quais tinham estado envolvidos em atividades agrícolas desde a infância. No presente estudo, foram realizadas visitas durante o período de abril de 2007 até janeiro de 2008; entrevistas não estruturadas foram feitas para obter dados sobre a história de vida, incluindo os períodos anteriores ao assentamento, durante a ocupação e atual. Para obter informações sobre os tipos de cultivo, a origem e circulação das variedades produzidas e a dinâmica de circulação das sementes e propágulos, foram realizadas entrevistas semi-estruturadas, e para levantar os dados socioeconômicos, foram aplicados questionários estruturados (BERNARD, 1988; VIERTLER, 2002). Para os dados gerais da população assentada, foi consultado o cadastro mantido pela agente comunitária de saúde do assentamento na época da pesquisa.

Para a identificação das plantas alimentares, foi coletado e herborizado material botânico das espécies e variedades encontradas (MING, 1996), que foram identificadas pelas autoras e pelos seguintes especialistas: Alisson Fernando Chiorato, Instituto 
Agronômico de Campinas - IAC; Arlete Marchi Tavares de Melo, Instituto Agronômico de Campinas - IAC; Carlos Alberto Scapim, Universidade Estadual de Maringá - UEM; Elisabeth Ann Veasey, Escola Superior de Agricultura "Luiz de Queiroz"; Edson Shigueaki Nomura, Agência Paulista de Tecnologias dos Agronegócios - APTA-SP; Helvécio Della Coletta Filho, Centro de Citricultura; Herculano Medina Filho, Instituto Agronômico de Campinas - IAC; Valdely Ferreira Kinupp, Instituto Federal do Amazonas - IFAM.

Os resultados foram analisados de forma qualitativa, com o auxílio de estatística descritiva; para avaliar se existe correlação entre a circulação de variedades e o acervo mantido pelo agricultor, foi utilizado o teste de correlação de Spearman, utilizando como variáveis o numero de relações de circulação (doações e recebimentos) e a quantidade de variedades (SIEGEL, 1975; AYRES et al., 2008).

\section{Resultados e Discussão}

\section{Caracterização do assentamento}

A população residente total é de 519 habitantes ( $55 \%$ do sexo masculino e $45 \%$ do sexo feminino), dos quais cerca de $48 \%$ têm até 20 anos de idade, cerca de $25 \%$ têm de 21 a 40 anos e $26 \%$ estão acima de 40 anos. Em relação à ocupação declarada, a totalidade da população adulta (18 anos ou mais) se autodenomina produtor rural. Somente $1,6 \%$ se autodeclararam aposentados, embora a população acima de 61 anos represente $5 \%$ da população. Apenas $0,8 \%$ declarou ter outras ocupações entre os homens (marceneiro, pedreiro, operador de máquinas, entre outros), e apenas $0,4 \%$ entre as mulheres (do lar, agente comunitária de saúde $)^{3}$. Algumas estratégias de produção são comuns a boa parte dos assentados: (a) o cultivo de café, recentemente estabelecido, e que ainda não produziu a primeira safra; (b) a exploração do eucalipto, e (c) cultivo de plantas hortícolas e de frutas, com venda esporádica do excedente (ITESP, 2006).

3 Dados do cadastro da agente comunitária de saúde.

\section{Caracterização dos agricultores}

\section{abordados no estudo}

Em três, dos dez lotes amostrados, participaram da pesquisa apenas os homens, em dois lotes as mulheres foram as informantes e em cinco lotes houve a participação do casal. Os informantes têm, em média, 54 anos (amplitude de 42 a 69 anos) e residem no próprio lote. O numero médio de habitantes por domicilio nos lotes amostrados é de 3,5, convivendo, geralmente, no mesmo domicílio, duas ou três gerações; em três casos, os filhos moram, com suas respectivas famílias, no mesmo lote, mas em domicílios diferentes. A idade mediana total foi de 38,7 anos, o que indica ser um grupo predominantemente adulto.

Considerando os filhos adultos, tanto homens como mulheres $(n=48)$, cerca de $60 \%$ residem fora do assentamento, principalmente nas cidades do entorno, como Moji-Mirim, Itapira, Conchal, Arthur Nogueira, Hortolândia e Campinas; 54\% exercem atividades de cunho urbano, 27\% trabalham em atividades rurais assalariadas, como na lavoura de tomate ou laranja, e 19\% não exercem atividades remuneradas (estudante, dona-de-casa ou desempregado). A proporção de mão-de-obra disponível, em relação a mão-de-obra utilizada na lavoura, é muito baixa (Tabela 1), ressaltando assim a falta de envolvimento dos jovens no trabalho agrícola, um fato que tem ocorrido em várias partes do Brasil e que reflete diretamente na estrutura e dinâmica da agrobiodiversidade mantida pelos agricultores (CULTRERA et al., 2006; AMOROZO, 2010). O relato de um agricultor exemplificou este dado quando ele disse que tem deixado de plantar mandiocas bravas, pois já não tem mais força para fazer a farinha, e nenhum filho ou neto tem interesse em aprender a fazer.

TABELA 1: Proporção de mão-de-obra disponível por mão-de-obra utilizada na lavoura e local de residência dos filhos com 18 anos ou mais.

\begin{tabular}{lcc} 
& filhos & filhas \\
\hline Mão de obra disponível * & 31 & 17 \\
Mão de obra utilizada & 5 & 2 \\
Proporção & 0,16 & 0,12 \\
\hline Reside no Assentamento & $41,9 \%$ & $35,3 \%$ \\
Reside em outros locais & $58,10 \%$ & $64,70 \%$ \\
\hline
\end{tabular}

* Considera-se mão-de-obra disponível todos os filhos com 18 anos ou mais. 
Todos os informantes são oriundos do estado de Minas Gerais, principalmente do Alto Jequitinhonha, região onde a agricultura é baseada em unidades familiares, com baixo dinamismo econômico, condições socioeconômicas desfavoráveis e migrações sazonais e definitivas (GALIZONI, 2000). A maioria migrou há aproximadamente 30 anos para a região nordeste do estado de São Paulo (que inclui o município de Moji-Mirim). Sua principal atividade continuou sendo na agricultura, porém em atividades assalariadas na agroindústria (colheita de cana-de-açúcar e laranja). Os agricultores abordados neste trabalho praticam principalmente agricultura de subsistência, com predomínio de cultivo de mandioca, milho e feijão, com venda de excedente; também produzem carvão com eucalipto remanescente do Horto e começaram a cultivar café. Não utilizam nenhum tipo de insumos químicos e técnicas de irrigação, e suas roças geralmente são diversificadas e consorciadas, por exemplo, com milho e abóbora ou feijão, mandioca e café, e quiabo e feijão. Neste ponto, encontra-se, nas técnicas de cultivo desses agricultores, concordância com alguns dos conceitos agroecológicos descritos por Altieri (2000).

\section{As variedades}

Neste trabalho, foram levantadas no total 139 variedades de cultivos alimentares, distribuídas em 55 espécies, pertencentes a 28 famílias botânicas (Tabela 2); 44\% são propagadas por meio de mudas (a grande maioria dessas são frutíferas); $34 \%$ por sementes (milho, feijão, abóbora) e $22 \%$ pelas partes vegetativas, como caule e brotos (mandioca e cana-de-açucar).

As culturas com maior número de variedades foram a banana (13\% do total), o milho e o feijão (cada uma com $11 \%)$, seguidas pela mandioca $(9 \%)$, cana-de-açucar (8\%), e abóbora (5\%); as outras frutíferas somam $24 \%$ do total das variedades e os restantes $19 \%$ correspondem a outras culturas, como arroz, coloral, taioba etc. Vale ressaltar que estas variedades foram identificadas de acordo com critérios dos agricultores. No caso da banana, 15 das 19 variedades localmente reconhecidas tiveram correspondência com dez cultivares agronômicos; não foi possível, porém, saber se tal fato ocorreu com outras espécies (Tabela 3).
Apenas 11 variedades são plantadas por $50 \%$ ou mais dos 10 agricultores, entre elas, a mandioca amarela (100\%), banana-maçã, café (70\%), milho e amora comuns $(60 \%)$. Em contraste, uma grande parte $(55 \%)$ tem frequência muito baixa, sendo plantada por apenas um agricultor (Tabela 2; Figura 1). Esta distribuição é semelhante à encontrada em diversas situações, tanto em comunidades tradicionais (EMPERAIRE; PERONI, 2007; AMOROZO, 2000; 2008) como entre agricultores familiares não tradicionais (ANGELO; AMOROZO, 2006). Constatou-se que $54 \%$ das variedades são oriundas do estado de Minas Gerais, em especial do Vale do Jequitinhonha, de onde vem a maior parte dos agricultores que fizeram parte do estudo. Em média, $70 \%$ das variedades de banana, mandioca, milho, cana, abóbora e feijão foram trazidas de Minas Gerais. No entanto, a maioria delas tem distribuição restrita entre os agricultores, exceção feita à banana mixui, coloral comum e mamão papaia, presentes na metade dos lotes investigados. As frutíferas são predominantemente do estado de São Paulo (76\%), na maioria das vezes originadas de mudas comercializadas em viveiros, embora haja casos de variedades tradicionais, como a manga-coquinho e a manga-rosa (LORENZI et al., 2006); também foram encontradas mudas feitas a partir de sementes de frutos comprados ou ganhos para consumo, além de casos onde a planta já existia no lote antes da ocupação. 
TABELA 2: Espécies alimentares citadas pelos agricultores do assentamento rural XII de Outubro-Moji-Mirim - SP.

\begin{tabular}{|c|c|c|c|c|c|c|c|}
\hline Familia & Nome Cientifico & Nome Popular & Varidades & Freq. & $\begin{array}{l}\text { Origem do } \\
\text { propágulo }\end{array}$ & $\begin{array}{l}\text { Registro } \\
\text { de coleta }\end{array}$ & $\begin{array}{c}\text { Determi- } \\
\text { nador }\end{array}$ \\
\hline Alliaceae & Allium sativum L. & Alho & & 1 & MG & 135 & CRA \\
\hline \multirow[t]{11}{*}{ Anacardiaceae } & Anacardium occidentale L. & Caju & & 2 & SP & 78 & VFK \\
\hline & Mangifera indica $\mathrm{L}$. & Manga & Coquinho & 3 & SP & 56 & VFK \\
\hline & & & Coração-de-boi & 3 & SP & 29 & VFK \\
\hline & & & Embu & 1 & SP & 66 & VFK \\
\hline & & & Espada & 5 & SP & $240^{\prime}-b$ & VFK \\
\hline & & & Grande & 1 & MG & $192 ’$ & VFK \\
\hline & & & Mamão & 1 & $\mathrm{SP}$ & $189^{\prime}$ & VFK \\
\hline & & & Palmer & 2 & SP & 77-b & VFK \\
\hline & & & Rosa & 1 & SP & $191^{\prime}$ & VFK \\
\hline & Spondias purpurea L. & Seriguela & & 2 & SP & 112 & VFK \\
\hline & Spondias tuberosa Arruda & Imbu & & 2 & MG & 109 & VFK \\
\hline Annonaceae & Rollinia mисова (Jacq.) Baill. & Fruta-do-conde & & 1 & $\mathrm{SP}$ & 213 & VFK \\
\hline \multirow[t]{3}{*}{ Araceae } & Colocasia esculenta (L.) Schott. & $\begin{array}{l}\text { Coió-chinês } \backslash \\
\text { inhame }\end{array}$ & & 1 & MG & 69 & EAV \\
\hline & Colocasia esculenta (L.) Schott. & Inhame-rosa & & 1 & MG & 94 & EAV \\
\hline & $\begin{array}{l}\text { Xanthosoma sagittifolium (L.) } \\
\text { Schott. }\end{array}$ & Taioba & & 4 & MG & 22 & EAV \\
\hline Araucariaceae & Araucaria angustifolia (Bertol.) & Pinhão & & 1 & $\mathrm{SP}$ & 117 & VFK \\
\hline Arecaceae & Cocos nucifera $\mathrm{L}$ & Coco & & 1 & MG & 214 & VFK \\
\hline \multirow[t]{2}{*}{ Bixaceae } & Bixa orelana $\mathrm{L}$. & Coloral & Comum & 5 & MG & 70 & VFK \\
\hline & & & Vermelho & 1 & MG & 215 & VFK \\
\hline Bromeliaceae & Ananas comosus (L.) Merr & Abacaxi & & 4 & SP & 216 & VFK \\
\hline \multirow[t]{3}{*}{ Caricaceae } & Carica papaya $\mathrm{L}$. & Mamão & Formosa & 1 & $\mathrm{SP}$ & 167 & VFK \\
\hline & & & Papaia & 5 & MG & 73 & VFK \\
\hline & & & Rosa & 1 & SP & $188^{\prime}$ & VFK \\
\hline Caryocaraceae & Caryocar brasiliense Camb. & Pequi & & 2 & SP & 130 & CRA \\
\hline \multirow[t]{12}{*}{ Curcubitaceae } & Cucurbita pepo L. & Abobrinha & Abobrinha & 1 & SP & 77 & AMT \\
\hline & Cucumis anguria $\mathrm{L}$. & Machiche & & 1 & MG & 49 & VFK \\
\hline & Cucurbita maxima Duch. & Abóbora & Moranga & 4 & MG & 23 & AMT \\
\hline & Cucurbita moschata Duch. & Abóbora & Abóbora & 2 & MG & 78 & AMT \\
\hline & & & Jacarezinho & 1 & MG & 76 & AMT \\
\hline & & & Jerimum & 2 & $\mathrm{SP}$ & 55 & AMT \\
\hline & & & Menina & 2 & SP & 136 & AMT \\
\hline & & & Mineira & 2 & MG & 57 & AMT \\
\hline & & & Mineira-branca & 1 & MG & 135 & AMT \\
\hline & & & Mineira-rajada & 1 & MG & 134 & AMT \\
\hline & Cyclanthera pedata (L.) Schrad & Machicho-fofo & & 1 & MG & 25 & VFK \\
\hline & Lagenaria sp. & Caxi & São-Tomé & 1 & SP & 217 & CRA \\
\hline \multirow[t]{2}{*}{ Euphorbiaceae } & Manihot esculenta Crantz & Mandioca & Amarela (roxa) & 10 & SP & $58-\mathrm{A}$ & EAV \\
\hline & & & Amarela (verde) & 2 & SP & $58-\mathrm{B}$ & EAV \\
\hline
\end{tabular}




\begin{tabular}{|c|c|c|c|c|c|c|c|}
\hline & & & $\begin{array}{l}\text { Braba } \\
\text { (piriquita) }\end{array}$ & 1 & MG & 47 & EAV \\
\hline & & & Caramuquenga & 1 & MG & 50 & EAV \\
\hline & & & Casadinha & 1 & MG & 46 & EAV \\
\hline & & & Mandiocossu & 2 & MG & 10 & EAV \\
\hline & & & Mole & 1 & MG & 45 & EAV \\
\hline & & & Pernambuco & 1 & SP & 218 & EAV \\
\hline & & & $\begin{array}{l}\text { Pocadeira }= \\
\text { sequinha }\end{array}$ & 1 & MG & 44 & EAV \\
\hline & & & Porto-seguro & 1 & MG & 48 & EAV \\
\hline & & & Rei-do-sono & 1 & MG & 122 & EAV \\
\hline \multirow[t]{17}{*}{ Fabaceae } & Arachis hypogaea L. & Amendoim & & 1 & SP & 219 & CRA \\
\hline & Phaseolus vulgaris L. & Feijão & Amendoim & 1 & MG & 33 & $\mathrm{AFC}$ \\
\hline & & & Anão & 1 & $\mathrm{SP}$ & 92 & $\mathrm{AFC}$ \\
\hline & & & Bico-de-ouro & 1 & MG & 220 & $\mathrm{AFC}$ \\
\hline & & & Carioca & 2 & SP & $235^{\prime}$ & $\mathrm{AFC}$ \\
\hline & & & $\begin{array}{l}\text { Cafezinho/ } \\
\text { mulatinho/ } \\
\text { Parana }\end{array}$ & 1 & MG & 221 & $\mathrm{AFC}$ \\
\hline & & & Fava & 4 & MG & $17-\mathrm{B}$ & $\mathrm{AFC}$ \\
\hline & & & Morumbé & 1 & MG & 32 & $\mathrm{AFC}$ \\
\hline & & & Pitoco & 1 & MG & 17 & $\mathrm{AFC}$ \\
\hline & & & Preto & 1 & MG & 222 & $\mathrm{AFC}$ \\
\hline & & & Roxinho & 2 & MG & 18 & $\mathrm{AFC}$ \\
\hline & Cajanus cajan (L.) Millsp & & $\begin{array}{l}\text { Andu-comum/ } \\
\text { preto }\end{array}$ & 4 & MG & $195^{\prime}$ & $\mathrm{AFC}$ \\
\hline & & & $\begin{array}{l}\text { Andu-ervilha/ } \\
\text { branco }\end{array}$ & 3 & MG & $196^{\prime}$ & $\mathrm{AFC}$ \\
\hline & Vigna unguiculata (L.) Walp & & Catador & 2 & SP & 54 & $\mathrm{AFC}$ \\
\hline & & & De corda & 3 & MG & 19 & $\mathrm{AFC}$ \\
\hline & & & Vagem & 1 & MG & 223 & $\mathrm{AFC}$ \\
\hline & Inga edulis Mart. & Ingá & & 2 & MG & 108 & VFK \\
\hline \multirow[t]{3}{*}{ Lauraceae } & Cinnamomum verum J.Presl & Canela & & 2 & SP & 115 & EAV \\
\hline & Persea americana Mill. & Abacate & Comum & 3 & SP & $237^{\prime}$ & VFK \\
\hline & & & Manteiga & 2 & $\mathrm{SP}$ & 89-A & VFK \\
\hline Lythraceae & Punica granatum $\mathrm{L}$. & Romã & & 1 & SP & 224 & VFK \\
\hline Malpighiaceae & Malpighia glabra $\mathrm{L}$. & Acerola & & 3 & SP & 225 & VFK \\
\hline \multirow[t]{2}{*}{ Malvaceae } & Abelmoschus esculentus L. & Quiabo & Comum & 4 & SP & 226 & VFK \\
\hline & & & Caipira & 2 & MG & 59 & VFK \\
\hline \multirow[t]{4}{*}{ Moraceae } & $\begin{array}{l}\text { Artocarpus heterophyllus (Thunb.) } \\
\text { Merrill }\end{array}$ & Jaca & & 4 & SP & 227 & VFK \\
\hline & Ficus carica $\mathrm{L}$. & Figo & & 1 & MG & 116 & VFK \\
\hline & Morus nigra $\mathrm{L}$. & Amora & Comum & 6 & $\mathrm{SP}$ & 68 & VFK \\
\hline & & & Grande & 1 & SP & 28 & VFK \\
\hline \multirow[t]{2}{*}{ Musaceae } & Musa paradisiaca $\mathrm{L}$. & Banana & 2 cachos & 2 & SP & 40 & ESN \\
\hline & & & $\begin{array}{l}\text { Azedinha/ } \\
\text { menina }\end{array}$ & 1 & MG & 36 & ESN \\
\hline
\end{tabular}




\begin{tabular}{|c|c|c|c|c|c|c|c|}
\hline & & & Caturra & 1 & MG & 118 & ESN \\
\hline & & & Caturrinha & 3 & MG & $9 \backslash 41$ & ESN \\
\hline & & & Caturrona & 1 & MG & 2 & ESN \\
\hline & & & Dedo-de-moça & 4 & MG & 5 & ESN \\
\hline & & & Maçã & 7 & SP & $4 \backslash 170-B$ & ESN \\
\hline & & & Maranhão & 2 & MG & 6 & ESN \\
\hline & & & Mixui & 5 & MG & 7 & ESN \\
\hline & & & Nanica & 3 & $\mathrm{SP}$ & 101 & ESN \\
\hline & & & Nanicão & 4 & SP & 38 & ESN \\
\hline & & & Naniquinha & 1 & SP & 104 & ESN \\
\hline & & & Ourinho & 1 & MG & $170-A^{\prime}$ & ESN \\
\hline & & & Pão & 1 & SP & 121 & ESN \\
\hline & & & Prata & 4 & SP & $103^{\prime}$ & ESN \\
\hline & & & Prata-maça & 3 & SP & $106^{\prime}$ & ESN \\
\hline & & & $\begin{array}{l}\text { Quatro-cacho- } \\
\text { no-pé }\end{array}$ & 1 & MG & 8 & ESN \\
\hline & & & Roxa & 2 & MG & $108^{\prime}$ & ESN \\
\hline & & & São-Tomé & 1 & MG & 3 & ESN \\
\hline Myrtaceae & Eugenia uniflora Berg & Pitanga & & 1 & SP & $241^{\prime}-\mathrm{a}$ & VFK \\
\hline & Myrciaria cauliflora (Mart.) Berg. & Jabuticaba & & 4 & MG & 72 & VFK \\
\hline & Psidium guajava $\mathrm{L}$. & Goiaba & & 4 & SP & 228 & VFK \\
\hline Passifloraceae & Passiflora cincinnata Mast. & Maracujá & do mato & 1 & MG & 42 & $\overline{\text { CRA }}$ \\
\hline & Passiflora edulis Sims & & Azedo & 1 & $\mathrm{SP}$ & 85 & VFK \\
\hline & Passiflora sp. & Maracujina & & 1 & SP & 61 & CRA \\
\hline Poaceae & Oryza sativa $\mathrm{L}$ & Arroz & Agulhinha & 1 & SP & 229 & VFK \\
\hline & Saccharum officinarum L. & Cana-de- açucar & Caiana & 2 & MG & $12 \backslash 124$ & VFK \\
\hline & & & Caiana-preta & 1 & SP & $175^{\prime}$ & VFK \\
\hline & & & Cana-da-usina & 4 & SP & $123 \backslash 176$ & VFK \\
\hline & & & Cento-vinte & 2 & MG & $60 \backslash 107$ & VFK \\
\hline & & & De-burro & 1 & MG & 13 & VFK \\
\hline & & & Maravilha & 1 & MG & 15 & VFK \\
\hline & & & Pó-de-arroz & 1 & MG & 14 & VFK \\
\hline & & & Roxalina & 1 & MG & 16 & VFK \\
\hline & Zea mays L. & Milho & Alho & 1 & MG & 230 & CAS \\
\hline & & & Anão & 1 & $\mathrm{SP}$ & 231 & CAS \\
\hline & & & Branco & 1 & MG & 189 & CAS \\
\hline & & & Caleturo & 1 & MG & 190 & CAS \\
\hline & & & Cateto & 1 & $\mathrm{MG}$ & 51 & CAS \\
\hline & & & Comum & 6 & SP & 127 & CAS \\
\hline & & & Doce & 1 & SP & 43 & CAS \\
\hline & & & Gentino & 1 & MG & 232 & CAS \\
\hline & & & Hibra & 3 & MG & 197 & CAS \\
\hline & & & Pipoca & 2 & MG & 124 & CAS \\
\hline & & & Preto/Paia-preta & 2 & MG & 125 & CAS \\
\hline
\end{tabular}




\begin{tabular}{|c|c|c|c|c|c|c|c|}
\hline & & & Sabugo-fino & 2 & MG & 93 & CAS \\
\hline & & & São-Paulo & 1 & MG & 52 & CAS \\
\hline Rosaceae & Prunus persica (L.) Batsch & Pessego & & 2 & SP & 63 & VFK \\
\hline Rubiaceae & Coffea arabica $\mathrm{L}$. & Café & Catuaí & 1 & MG & 234 & HMF \\
\hline & & & Comum & 7 & SP & 235 & HMF \\
\hline Rutaceae & C. sinensis $x$ C. reticulata & Laranja & Morcote & 1 & SP & 110 & $\mathrm{HDC}$ \\
\hline & Citrus aurantifolia $\mathrm{L}$. & Limão & Taiti & 5 & $\mathrm{SP}$ & 26 & $\mathrm{HDC}$ \\
\hline & Citrus limonia Osbeck & Limão & Galego & 1 & MG & $238^{\prime}$ & $\mathrm{HDC}$ \\
\hline & & & Vinagre & 1 & MG & 129 & $\mathrm{HDC}$ \\
\hline & Citrus reticulata Blanco & Laranja & Pokã & 2 & SP & 99 & $\mathrm{HDC}$ \\
\hline & Citrus sinensis (L.) Osbeck & Laranja & Baiana & 2 & SP & 111 & $\mathrm{HDC}$ \\
\hline & & & Cravo & 1 & SP & 137 & $\mathrm{HDC}$ \\
\hline & & & Lima & 1 & SP & 64 & $\mathrm{HDC}$ \\
\hline & & & Melim & 1 & MG & 136 & $\mathrm{HDC}$ \\
\hline & & & Pera- coroa & 5 & SP & 30 & $\mathrm{HDC}$ \\
\hline & & & Pera- valensa & 1 & SP & 98-b & $\mathrm{HDC}$ \\
\hline Sapindaceae & Litchi chinensis Sonn & Lichia & & 1 & SP & 236 & VFK \\
\hline Solanaceae & Solanum betaceum Cav. & Jiló & De-árvore & 1 & MG & 21 & VFK \\
\hline Zingiberaceae & Curcuma longa $\mathrm{L}$. & Açafrão & Safroa & 1 & MG & $33-b$ & VFK \\
\hline 28 & 55 & & 139 & & & & \\
\hline
\end{tabular}

Alisson Fernando Chiorato; AMT=Arlete Marchi Tavares de Melo; CRA=Carolina Ribeiro Araujo; CAS= Carlos Alberto Scapim; EAV= Elisabeth Ann Veasey; ESN=Edson Shigueaki Nomura; HDC=Helvécio Della Coletta Filho; HMF=Herculano Medina Filho; VFK=Valdely Ferreira Kinupp.

TABELA 3: Variedades de banana reconhecidas localmente e cultivares agronômicos correspondentes.

\begin{tabular}{|c|c|c|c|}
\hline Variedade & Cultivar agronômico* & Variedade & Cultivar agronômico* \\
\hline Dois-cachos,quatro-cachos-no-pé & São-mateus & Maranhão & Maranhão \\
\hline Azedinha/menina & Mysore ou Thap Maeo & Mixui & Não identificada \\
\hline Caturra & Não identificada & Naniquinha & Não identificada \\
\hline Caturrinha, nanica, nanicão & Nanica & Pão & Não identificada \\
\hline Caturrona & Nanicão & Prata, prata-maçã & Enxerto ou prata-anã \\
\hline Dedo-de-moça, ourinho & Ouro & Roxa & Caru-roxa \\
\hline Maçã & Maçã ou enxerto prata-anã & São-tomé & São-tomé \\
\hline
\end{tabular}

*identificados por ESN.

Das variedades que vieram de Minas Gerais, $83 \%$ foram trazidas desde o início da ocupação, mas algumas foram introduzidas posteriormente por ocasião de visitas à terra natal, ou por parentes e amigos. Este trânsito de variedades ocorre até os dias atuais, principalmente através de dois agricultores (GL e NM) que vão a Minas Gerais anualmente; por exemplo, neste último ano houve a introdução de duas novas variedades de feijão (morumbé e amendoim), abóbora e quiabo.
Da mesma forma que novas variedades são introduzidas, outras se perdem, conferindo uma dinâmica à diversidade mantida ao longo do tempo. Embora com certo grau de imprecisão, foi possível estabelecer uma lista de 22 variedades que foram lembradas pelos agricultores da amostra e que se perderam ao longo desses dez anos de ocupação no assentamento (Tabela 4); algumas perdas ocorreram no período em que a pesquisa estava sendo realizada, com destaque para os 
FIGURA 1: Frequência das variedades entre os agricultores.

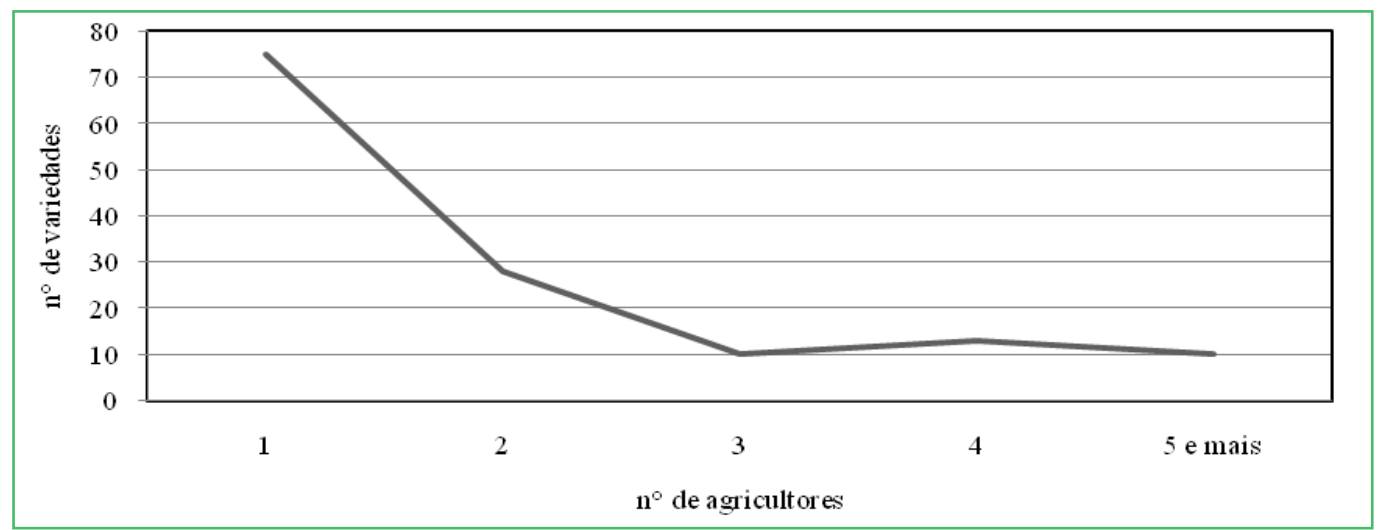

TABELA 4: Variedades perdidas.

\begin{tabular}{ll|ll}
\hline \multicolumn{1}{c}{ Cultura } & \multicolumn{1}{c}{ Variedade } & \multicolumn{1}{c}{ Cultura } & Variedade \\
\hline \hline Abóbora & Jacaré-redonda e comprida & Café & Celeste \\
Agrião & De tempero & Feijão & De metro \\
Amendoim & Cavalo & Gergelim & \\
& Preto & Inhame & Roxo \\
Arroz & Amarelão & Limão & Doce \\
& Sabará & Mandioca & Cabuquinha \\
Banana & Vermelho & Pão-da-china \\
& De semente & Sertãozinho \\
Cana-de-açúcar & Canguçu/carritelo & & Caturrinha \\
& Java & & Mineiro-amarelo \\
\hline \hline
\end{tabular}

casos das mandiocas bravas cabuquinha, sertãozinho e pão-da-china, produzidas para fazer farinha, atividade esta abandonada pelo agricultor que as cultivava devido à falta de saúde e impossibilidade de reposição de mão-de-obra.

Além disso, houve 11 casos de variedades que foram perdidas por algum agricultor, mas outro agricultor continua cultivando. Neste sentido, ressaltase a importância da circulação das variedades para a manutenção da diversidade agrícola, pois mesmo se um agricultor perder a variedade, ele pode recorrer àqueles que já adquiriram a variedade anteriormente. Entre as variedades perdidas completamente, a grande maioria foi trazida de Minas Gerais (19 variedades) e se perdeu principalmente porque as plantas não se adaptaram às condições do assentamento (baixa produção e ataque de pragas e doenças). Contudo, a maioria dos agricultores diz que voltaria a cultivar as variedades perdidas, caso houvesse a oportunidade de readquirí-las. Relativo às perdas, também é oportuno refletir sobre as variedades que ainda não desapareceram, mas são cultivadas em micro-escala, apenas alguns pés no quintal para "não se perder raça", como os próprios agricultores dizem. Este fato ocorre principalmente com as variedades de mandioca, cana, açafrão, taioba, inhame e maxixe. Neste aspecto, tornam-se evidentes os critérios de ordem afetiva e estética como incentivo para a continuidade de cultivo das variedades (EMPERAIRE et al., 2001). Nota-se que tais variedades estão numa linha muito tênue entre o desaparecimento e a conservação, principalmente ao se levar em conta o desinteresse dos mais jovens pelo trabalho na lavoura. 
A grande maioria (79\%) das variedades é cultivada a partir de mudas produzidas pelo próprio agricultor ou ganhas; apenas $21 \%$ são provenientes do mercado, principalmente as frutíferas, como cítricos e manga. Os outros casos de compra de propágulo referem-se às variedades comerciais de milho e abóbora (três variedades compradas), feijão, café e cana (uma variedade comprada); no caso da abóbora, ressalta-se que o fruto é adquirido no comércio, e após seu consumo, aproveitam-se as sementes. Não há nenhum caso de propágulos de mandioca e banana comprados (Figura 2).

Em relação ao uso dos produtos agrícolas, observa-se que a grande maioria destina-se ao consumo da família e amigos (87\%), podendo o excedente ser ocasionalmente comercializado. Apenas 5\% das variedades são cultivadas com o principal objetivo de comercialização dos produtos, por exemplo, o café, a mandioca amarela e o quiabo; milho e cana são utilizados na produção de ração para as criações animais do próprio lote. As variedades produzidas para venda, com exceção da mandioca amarela, são variedades comerciais cultivadas em maior escala. Dessa forma, encontra-se no assentamento uma configuração da manutenção da diversidade descrita por Bellon (1996) e por Brush (1992) nos Andes a respeito de batatas: frente ao ingresso na economia de mercado, os agricultores adotam algumas variedades altamente produtivas, as quais plantam em áreas mais extensas, e mantêm, em uma área reduzida, uma reserva de variedades tradicionais.

\section{O acervo de variedades dos agricultores}

O número de variedades cultivadas por agricultor varia entre 7 e 54; no geral, todos os agricultores investigados possuem um conjunto bastante diverso de cultivos, contudo há agricultores que se destacam devido à maior riqueza de variedades e também maior heterogeneidade de cultivos (Figura 3).

Alguns agricultores podem ser considerados fonte de diversidade de certos tipos de cultivos, por exemplo, o agricultor ZP é uma boa fonte de variedades de abóboras e bananas, já o PM cultiva muitas variedades de mandioca, assim como o GL, que possui grande variedade de banana, milho e cana. Assim, em parte, as coleções de cada agricultor têm uma especificidade e se complementam, demonstrando que a contribuição individual enriquece o acervo de variedades como um todo. No entanto, alguns agricultores vão mais além, mantendo maior diversidade que os demais, como GL e PM. Estes dois agricultores também se destacam em relação ao número de etnovariedades, ou variedades locais, com 32 e 22 respectivamente; todos os outros as possuem, mas em quantidades menores, em sua maioria variando entre 5 e 10. Além disso, GL (e também NM) mantém contato regular com a região de onde é originário, de lá trazendo novas variedades. Estes agricultores aproximam-se do perfil de agricultores "guardiões" ou "nodais", pela alta agrobiodiversidade

FIGURA 2: Meios de obtenção das variedades.

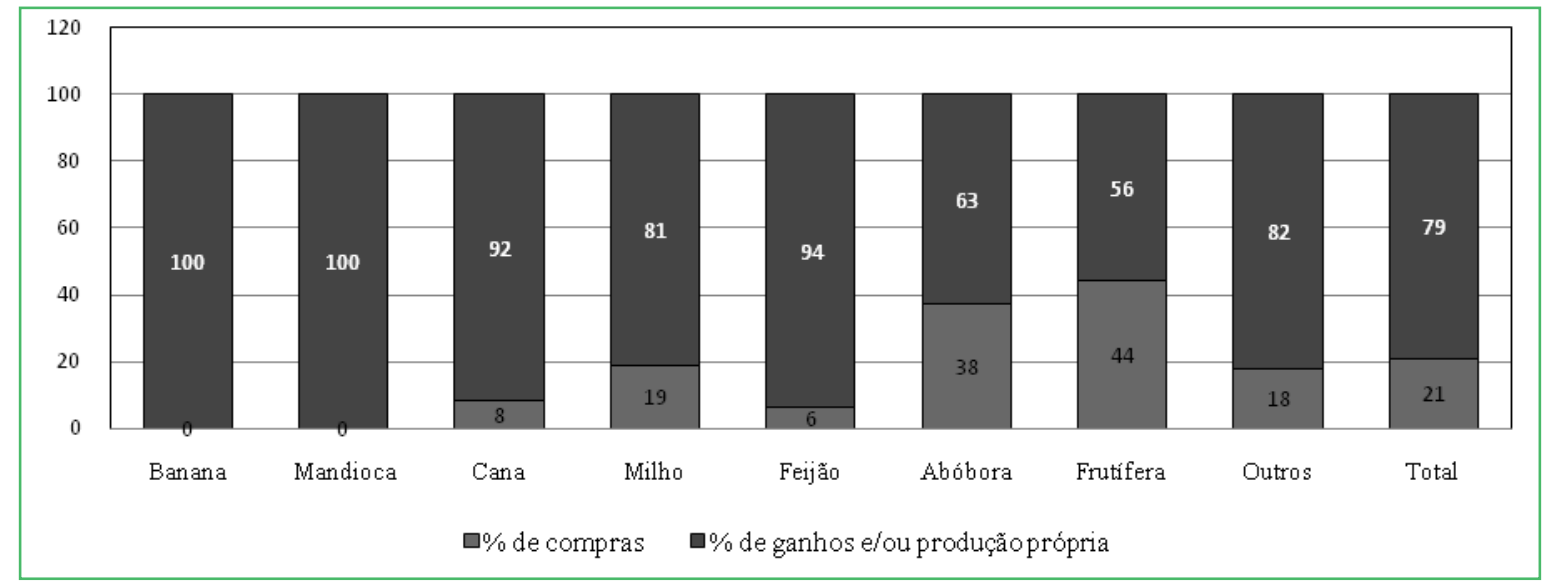


FIGURA 3: Número de variedades para cada agricultor.

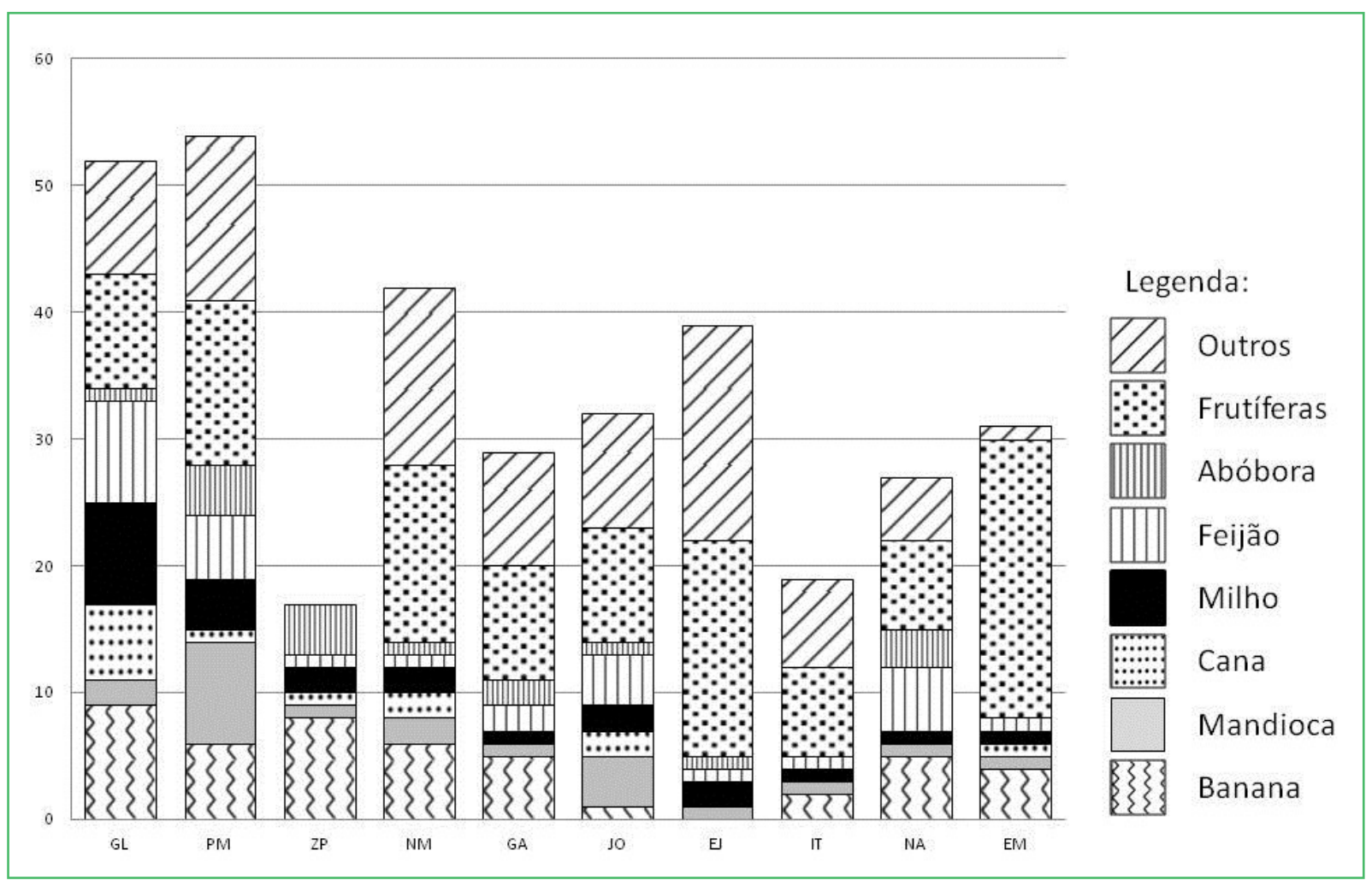

que mantêm, destacando as etnovariedades trazidas de Minas Gerais, pela busca de novas variedades e ativa participação na disseminação de propágulos na rede social do assentamento (SUBEDI et al., 2003). Em média, cada agricultor possui cinco variedades comerciais, destacando o agricultor JO, que possui 12 , principalmente de frutíferas. A maioria dos agricultores recordou-se de variedades que se perderam, com exceção dos agricultores ZP, JO, EJ e EM.

\section{A circulação}

Neste estudo, foram contabilizadas 187 relações de doação de material de plantio entre os agricultores, abrangendo, além dos dez agricultores da amostra, mais 40 agricultores do assentamento, sendo $73 \%$ homens e 27\% mulheres. Estas relações ocorrem principalmente entre os agricultores do assentamento, sendo $31 \%$ das relações entre os agricultores da amostra, 66\% entre algum entrevistado e outro assentado e, por fim, apenas $3 \%$ entre algum entrevistado e outro agricultor de fora do assentamento. Os agricultores da amostra também relataram receber material de plantio, desta forma, foram registradas 41 relações de recepção, incluindo, além dos próprios agricultores da amostra, mais sete agricultores do assentamento.

As relações de circulação entre os agricultores da amostra e seus familiares são minoria, apenas $5 \%$ do total, em parte porque, segundo os informantes, são poucos os parentes que estão estabelecidos no assentamento. Isto contrasta com a situação encontrada em comunidades mais antigas ou tradicionais, onde geralmente os parentes convivem em uma mesma vizinhança e trocam intensamente germoplasma entre si (CHERNELA, 1987; AMOROZO, 1996; 2002; BADSTUE et al., 2007; entre outros).

O ato de doar e receber sementes e propágulos é visto com naturalidade entre os agricultores, podendo servir para estreitar laços entre vizinhos, alem de ser usado como um método de prevenção de futuras perdas. Neste estudo, foram relatados três casos onde os agricultores recorreram aos vizinhos para recuperar variedades perdidas. Predominantemente, tais relações consistem 
em doações, havendo apenas $2 \%$ referentes à venda, e nenhum caso de troca imediata, as trocas ocorrem ao longo do tempo. Geralmente essas doações ocorrem por interesse dos receptores e de forma espontânea, durante visitas informais; a venda de sementes é vista por alguns agricultores como uma prática indevida; disse um deles que seus pais lhe ensinaram que nunca se deve negar um pouco de sementes para ninguém, e que nunca se pode vender sementes e mudas. As quantidades sempre são pequenas, apenas para experimentação e satisfação da curiosidade, a fim de avaliar as qualidades da variedade, entre elas, o sabor e produção. $67 \%$ das atividades de circulação mencionadas pelos agricultores envolvem variedades trazidas de Minas Gerais, aquelas que despertam mais interesse e curiosidade dos agricultores.

As plantas cujos propágulos são sementes tiveram a maior circulação ( $47 \%$ do total), seguidas por aquelas cujos propágulos são partes vegetativas (29\%). Embora tenham sido levantadas mais plantas cuja forma de propagação é por mudas, observou-se que estas foram as que menos circularam (24\%). A circulação preferencial das sementes pode estar relacionada à facilidade de transporte e armazenagem deste material, em comparação com outros materiais de propagação. Em reforço a esta ideia, observa-se que 35\% das 67 variedades que nunca circularam são mudas. Vale ressaltar que as variedades comerciais geralmente não circulam, apenas 12\% delas já circularam. Embora um banco de sementes comunitário estivesse em fase de implantação no assentamento, ele praticamente não teve influência na rede social de trocas dos dez entrevistados, durante o período da pesquisa.

Foram relatados mais casos de doação do que recebimento de material de plantio, destacando, como principal doador, o agricultor NM, seguido pelos agricultores GL, PM e ZP; considerando relações de recebimento, percebe-se que os agricultores GA, EJ são os principais receptores. Coomes e Ban (2004), estudando trocas de propágulos entre agricultores de uma vila na Amazônia peruana, encontraram situação oposta: os agricultores registraram maior número de relações de recebimento do que de doação. No caso do presente estudo, a discrepância entre doações e recepções pode ter tido influência de falhas de memória dos agricultores; para contornar em parte este problema, as relações de circulação foram agrupadas. Não foi detectada correlação significativa entre a quantidade de variedades cultivadas no lote e a quantidade de relações de circulação, porém, em vista do exposto acima, este resultado tem que ser visto com cautela, pois estas relações podem estar subestimadas (Tabela 5).

TABELA 5: Correlação entre total de relação de circulação e total de variedades.

GL PM ZP NM GA JO EJ IT NA EM Total

Total relações

de circulação

$\begin{array}{lllllllllll}33 & 57 & 19 & 20 & 22 & 12 & 9 & 8 & 37 & 11 & 228\end{array}$

Total variedades

$\begin{array}{lllllllllll}52 & 54 & 17 & 42 & 29 & 32 & 39 & 17 & 27 & 31 & 340\end{array}$

Coeficiente de Spearman $(\mathrm{rs})=0.4195 ; \mathrm{t}=1.3069 ;(\mathrm{p})=0.2275$

\section{Considerações Finais}

Os resultados do presente estudo evidenciam que os agricultores assentados, originários de áreas de agricultura de subsistência, e que ainda a praticam nos assentamentos, retêm práticas que mantêm a agrobiodiversidade. O assentamento rural XII de Outubro situa-se em uma região de grande dinamismo econômico, onde a agricultura moderna é predominante e alberga famílias com diferentes procedências e experiências de vida. Apesar disso, os agricultores aqui enfocados, que ocupam cerca de $11 \%$ dos lotes do assentamento, mantêm, em conjunto, mais de cem variedades de diversos cultivos; a rede de circulação de sementes e propágulos na qual atuam envolve vários outros agricultores do assentamento e também de fora, incluindo a entrada de materiais das regiões de origem de alguns deles. Isto demonstra que há um potencial para uso, conservação e valorização das variedades tradicionais no assentamento.

Duas questões colocam-se a respeito do aproveitamento deste potencial. A primeira é sensibilizar outros agricultores, mais voltados para a agricultura comercial e sem a bagagem cultural dos agricultores tradicionais, para participar na consecução deste objetivo. 
A segunda diz respeito à presente falta de envolvimento das gerações mais jovens com as atividades agrícolas, comprometendo as perspectivas a médio e longo prazos de conservação de agrobiodiversidade on farm. Este desinteresse deve-se, em parte, às dificuldades e à pouca remuneração do trabalho, bem como à penetração de valores e aspirações urbanas no meio rural.

É necessário envidar esforços para elevar a qualidade de vida dos agricultores, investindo em infra-estrutura, serviços básicos e em oportunidades de realização pessoal. Modelos agrícolas, compatíveis com a manutenção da agrobiodiversidade, e que ao mesmo tempo, possam agregar valor aos produtos e elevar o nível de renda do agricultor, como por exemplo, o agroecológico, devem ser incentivados. Algumas iniciativas visando a esta meta estão sendo realizadas no assentamento atualmente, incluindo, entre outras: cursos de formação de Agentes de Assistência Técnica e Extensão Rural - ATER com ênfase em Agroecologia, promovidos pelo Departamento de Assistência Técnica e Extensão Rural - DATER, da Secretaria de Agricultura Familiar - SAF, do Ministério do Desenvolvimento Agrário - MDA, em parceria com a Universidade Estadual de Campinas - UNICAMP; a atuação da Rede Regional de Agroecologia Mantiqueira-Mogiana, programa promovido pela EMBRAPA - Meio Ambiente, com o objetivo de desenvolver e aprimorar a agricultura de base ecológica por meio de métodos participativos e valorização dos conhecimentos dos agricultores, visando à sua capacitação para o desenvolvimento de propriedades agroecológicas.

Em destaque para o assunto aqui abordado, coloca-se a implantação de um banco de germoplasma comunitário, iniciada pela Associação de Mulheres Agroecológicas - AMA, que congrega as agricultoras do próprio assentamento. Entretanto, muitos desafios foram encontrados, como a falta de um responsável pela administração diária do banco e falta de recursos para a sua manutenção, entre outros. Por isso, este projeto encontra-se suspenso, à espera de parcerias e apoio que ajudem as idealizadoras a superar tais desafios; um banco deste tipo, ao incluir propágulos trazidos das regiões de origem dos agricultores assentados, não só permitirá maior autonomia frente ao mercado, mas também irá contribuir para a valorização da cultura local, mantendo a biodiversidade agrícola associada a ela (STHAPIT et al, 2002; AMOROZO, 2007).

Em suma, o potencial do assentamento rural estudado para a manutenção e mesmo o incremento da agrobiodiversidade local com certeza deve existir também em pelo menos uma parcela dos assentamentos rurais que existem no Brasil. Porém, para que este potencial se concretize, vale ressaltar a necessidade de parcerias e políticas públicas que incentivem e apóiem os agricultores.

\section{Referências}

ALTIERI, M. A. Agroecologia: A dinâmica produtiva da agricultura sustentável. Porto Alegre: UFRGS, 2000. 110 p.

AMOROZO, M. C. M. Um sistema de agricultura camponesa em Santo Antonio do Leverger, Mato Grosso - Brasil. 1996. 266 f. Tese (Doutorado em Antropologia) - Universidade de São Paulo, São Paulo. 1996.

AMOROZO, M. C. M. Management and conservation of Manihot esculenta Crantz. Germ plasm by traditional farmers in Santo Antonio do Leverger, Mato Grosso State, Brasil. Etnoecologica, Mexico, v. 4, n. 6, p. 69-83, 2000.

AMOROZO, M. C. M. Agricultura tradicional, espaços de resistência e o prazer de plantar. In: ALBUQUERQUE, U. P.; ALVES, A. G. C.; SILVA, A. C. B. L.; SILVA, V. A. (Org.). Atualidades em etnobiologia e etnoecologia. Recife: Sociedades Brasileiras de Etnobiologia e Etnoecologia, 2002. p. 123-131.

AMOROZO, M. C. M. Construindo a sustentabilidade: Biodiversidade em paisagens agrícolas e a contribuição da etnobiologia. In: ALBUQUERQUE, U. P.; ALVES, A. G. C.; ARAÚJO, T. A. S. (Org.). Povos e paisagens: Etnobiologia, etnoecologia e biodiversidade no Brasil. Recife: NUPEEA/UFRPE, 2007. p. 76-88.

AMOROZO, M. C. M. Os Quintais - Funções, importância e futuro. In: GUARIM NETO, G.; CARNIELLO, M. A. (Org.). Quintais Mato-Grossenses: Espaço de conservação e reprodução de saberes. Cáceres: UNEMAT, 2008. p. 15-26.

AMOROZO, M. C. M. Diversidade agrícola em um cenário rural em transformação: Será que vai ficar alguém para cuidar da roça? In: MING, L. C.; AMOROZO, M. C. M.; KFFURI, C. W. (Org.). Agrobiodiversidade no Brasil - Experiências e caminhos da pesquisa. Recife: NUPEEA, 2010. p. 293-308.

ANGELO, G. A.; AMOROZO, M. C. M. Diversidade de tubérculos alimentícios em povoados rurais no município de Frutal, Minas Gerais, Brasil. In: ALBUQUERQUE, U. P.; MARINS, J. F. A.; ALMEIDA, C. F. C. B. R. (Org.). Tópicos em conservação e etnobotânica de plantas alimentícias. 1 ed. Recife: NUPEEA/ UFRPE, 2006. p. 119-140.

AYRES, M.; AYRES JR., M.; AYRES, D. L.; SANTOS, A. S. BioEstat 5.0. Pará: Soc. Civil Mamirauá/ MCT /Imprensa Oficial do Estado do Pará, 2008. 324 p. 
BADSTUE, L. B.; BELLON, M. R.; BERTHAUD, J.; RAMIREZ, A.; DAGOBERTO, F.; JUAREZ, X. The dynamics of farmers' maize seed supply practices in Central Valleys of Oaxaca, Mexico. World Development, Montreal, v. 35, p. 1579-1593, 2007.

BELLON, M. R. The dinamics of crop infraspecif diversity: A conceptual framework at the farmer level. Economic Botany, New York, v. 50, p. 26-39, 1996.

BELLON, M. R. Demand and supply of crop infraspecific diversity on farms: Towards a policy framework for on-farm conservation. CIMMYT Economics Working Paper, Mexico, v. 1, n. 1, p. 1-12, 2001.

BERGAMASCO, S. M. P. P.; NORDER, L. A. C. A alternativa dos assentamentos rurais: Organização social, trabalho e política. São Paulo: Terceira Margem, 2003. 191 p.

BERNARD, H. R. Research methods in cultural anthropology. Newbury Park: SAGE Publ., 1988. 520 p.

BIROL, E.; KONTOLEON, A.; SMALE, M. Farmer demand for agricultural biodiversity in Hungary's Transition Economy: A choice experiment approach. In: SMALE, M. (Ed.). Valuing crop biodiversity: On-farm genetic resources and economic chance. Oxfordshire: Ed. CAB Internacional, 2006. 312 p.

BROOKFIELD, H. Exploring agrodiversity. New York: Columbia University Press, 2001. 368 p.

BROWN, A.H.D.; JARVIS, D.I.; MYER, L.; GUARINO, L.;SMALE, M.; SADIKI, M., STHAPIT, B.; HODGKIN, T. A training guide for in situ conservation on-farm. 2000. Disponível em: <www.bioversityinternational.org/fileadmin/bioversity/ publications/.../611.pdf>. Acesso em: 21 maio 2008.

BRUSH, S. B. Ethnoecology biodiversity and modernization in Andean potato agriculture. Journal of Ethnobiology, Denton, v. 12, p. 161-185, 1992.

BRUSH, S. B. The issues of in situ conservation of crop genetic resources. In: BRUSH, S. B. (Ed.) Genes in the field: on-farm conservation of crop diversity. Roma: International Plant Resources Institute, 2000. p. 3-27.

CEPAGRI - Centro de Pesquisas Meteorologicas e Climaticas Aplicadas à Agricultura. Clima dos municípios paulistas. 2001. Disponível em <http://www.cpa.unicamp.br/outras-informacoes/ clima-dos-municipios-paulistas.html>. Acesso em: 07 março 2011. CHERNELA, J. M. Os cultivares de mandioca na área do Uapés. In: RIBEIRO, D. (Ed.). Suma etnológica brasileira: Etnobiologia. 2. ed. Petrópolis: FINEP, 1987. p. 151-158.

COOMES, O. T.; BAN, N. Cultivated plant species diversity in home gardens of an Amazonian Peasant Village in northeastern Peru. Economic Botany, New York, v. 53, p. 420-434, 2004.

CULTRERA, M.; AMOROZO, M. C. M.; MING, L. C.; SIQUEIRA, A.P.P. Semeando sementes, cultivando cultura: As plantas alimentares e a sua importância para a vida dos agricultores do assentamento XII de Outubro, Mogi Mirim, SP. In: SIMPÓSIO BRASILEIRO DE ETNOBIOLOGIA E ETNOECOLOGIA, VI, 2006, Porto Alegre. Anais... Porto Alegre: SBEE, 2006. Versão eletrônica.

EMPERAIRE, L.; PINTON, F.; SECOND, G. Manejo de la diversidad varietal de la yuca en la Amazonia del noroeste. Etnoecologica, Mexico, v. 5, n. 7, p. 38-59, 2001.

EMPERAIRE, L. Histórias de plantas, histórias de vida: uma abordagem integrada da diversidade agrícola tradicional na Amazônia. In: ALVES, A. G. C., ALBUQUERQUE, U.P.;
LUCENA, R. F. P. (Org.). Atualidades em Etnobiologia e Etnoecologia. Recife: NUPEEA/Sociedade Brasileira de Etnobiologia e Etnoecologia, v. 3, 2006. p. 189-198.

EMPERAIRE, L.; ELOY, L. The city, a center of agriculture in the Rio Negro? Boletim do Museu Paraense Emílio Goeldi, Ciências Humanas, Belém, v. 3, n.2, p. 195-211, 2008.

EMPERAIRE, L.; PERONI, N. Traditional management of agrobiodiversity in Brazil: A case study of manioc. Human Ecology, Ithaca, v. 35, n. 6, p. 761-768, 2007.

GALIZONI, F. M. A terra construída. Dissertação (Mestrado em Antropologia Social) - Universidade de São Paulo, São Paulo. 2000, 72 p.

GAVIOLI, F. R. Conservação e manejo da biodiversidade em um assentamento rural. Revista Brasileira de Agroecologia, Porto Alegre, v. 4, n. 2, p. 298-301, 2009. Resumos do VI CBA e II CLAA.

GIL, A. C. Métodos e técnicas de pesquisa social. 5. ed. São Paulo: Atlas, 1999. 206 p.

GIRARDI, E. P.; FERNANDES, B. M. A luta pela terra e a política de assentamentos rurais no Brasil: a reforma agrária conservadora. Agrária, São Paulo, n. 8, p. 73-98, 2008.

GODOY, A. S. Pesquisa qualitativa. Tipos fundamentais. Revista de Administração de Empresas, São Paulo, v. 35, n. 3, p. 20-29, 1995.

IBGE - INSTITUTO BRASILEIRO DE GEOGRAFIA E ESTATÍSTICA. Dados da PNAD 2000. 2000. Disponível em: $<$ http://www.ibge.gov.br>. Acesso em: 26 out. 2006.

INCRA - INSTITUTO NACIONAL DE COLONIZAÇÃO E REFORMA AGRÁRIA. Assentamentos estaduais administrados pelo ITESP. São Paulo, 2008a. Disponível em: <http://www.incra. gov.br/saopaulo/arquivos/0626704010.pdf>. Acesso em: 28 ago. 2008.

INCRA - INSTITUTO NACIONAL DE COLONIZAÇÃO E REFORMA AGRÁRIA. Assentamentos federais administrados pelo INCRA. São Paulo, 2008b. Disponível em: <http://www. incra.gov.br/saopaulo/arquivos/0626704009.pdf>. Acesso em: 28 ago. 2008 .

ITESP - INSTITUTO DE TERRAS DO ESTADO DE SÃO PAULO. Produção agrícola dos municipios do Estado de São Paulo. 2006. Disponível em: < http://www.itesp.sp.gov.br/br/info/ publicacoes/revistas.aspx>. Acesso em: 26 mar. 2008.

JANA, S. Some recent issues on the conservation of crop genetic resources in developing countries. Genome, Saskatoon, n. 42, p. 562-569, 1999.

LORENZI, H.; SARTORI, S. F.; BACHER, L.; LACERDA, M. T. C. Frutas brasileiras e exóticas vultivadas. Nova Odessa: Instituto Plantarum, 2006. 640 p.

MARTINE, G.; GARCIA, R. C. Os impactos sociais da modernização agrícolas. São Paulo: Ed. Caetés, 1987. 271 p.

MARTINS, P. S.; OLIVEIRA, G. C. X. Dinâmica evolutiva em roças de caboclos amazônicos. In: VIEIRA, I. C. G.; SILVA, J. M. C.; OREN, D. C.; D'INCAO, M. A. (Ed.). Diversidade biológica e cultural da Amazônia. Belém: Museu Paraense Emilio Goeldi, 2009. p. 373-391.

MAXTED, N.; GUARINO, L.; MYER, L.; CHIWONA, E. A. Towards a methodology for on-farm conservation of plant genetic 
resources. Genetic Resources and Crop Evolution, Dordrecht, v. 49, p. 31-46, 2002.

MING, L. C. Coleta de plantas medicinais. In: DI STASI, L. C. (Org.). Plantas medicinais: Arte e ciência. Um guia de estudo interdisciplinar. São Paulo: UNESP, 1996. p. 69-86.

PERONI, N.; KAGEYAMA, P. Y.; BEGOSSI, A. Molecular differentiation, diversity, and folk classification of "sweet" and "bitter" cassava (Manihot esculenta) in Caiçara and Caboclo management systems (Brazil). Genetic Resources and Crop Evolution, Dordrecht, v. 54, p. 1333-1349, 2007.

SIEGEL, S. Estatística não-paramétrica. São Paulo: McGrawHill do Brasil, 1975. 350 p.

SOARES, C. O. Institucionalização e relações sociais na atenção à saúde em um assentamento rural: $\mathrm{O}$ caso do Horto Vergel. 2005. 76 f. Dissertação (Mestrado em Engenharia Agrícola) Universidade Estadual de Campinas, Campinas. 2005.
STHAPIT, B.; RAO, R.; JARVIS, D. Conceptual basis of in situ conservation of sweet potato agrobiodiversity. In: RAO, R.; CAMPILAN, D. (Ed.). Exploring the complementarities of in situ and ex situ conservation strategies for Asian sweet potato genetic resources. Proceedings of the $3^{\text {rd }}$ International Workshop of the Asian Network for Sweet Potato Genetic Resources (ANSWER). Denpasar, Bali, Indonesia, 2-4 de outubro de 2001. Roma: IPGRI, 2002.

SUBEDI, A.; CHAUDHARY, P.; BANIYA, B. K. ; RANA, R. B.; TIWARI, R. K.; RIJAL, D. K.; STHAPIT, B. R.; JARVIS, D. I. Who maintains crop genetic diversity and how?: Implications for on-farm conservation and utilization. Culture \& Agriculture, Arlington, v. 25, n. 2, p. 41-50, 2003.

VIERTLER, R. B. Métodos antropológicos como ferramenta para estudos em Etnobiologia e Etnoecologia. In: AMOROZO, M. C. M.; MING, L. C.; SILVA, S. M. P. (Ed.). Métodos de coleta e análise de dados em etnobiologia, etnoecologia e disciplinas correlatas. Rio Claro: UNESP, 2002. p. 129-130. 